\title{
Structural Source of the Trap of ICT Advancement - Lessons from World ICT Top Leaders
}

\author{
Chihiro Watanabe \\ Tokyo Seitoku University, Japan and University of Jyvaskyla, Finland. \\ Kashif Naveed \\ University of Jyväskylä, Finland. \\ Weilin Zhao \\ Fujitsu Research Institute, Japan.
}

\begin{abstract}
In light of the significant consequence of the trap of dramatic advancement of information and communication technology (ICT) in the global economy, both nations and firms that have been compelling their productivity decline. This resulted in great stagnation of ICT advanced economies and therefore its structural sources were analyzed.

Based on an empirical analysis tracing, the trend in marginal productivity of ICT and its subsequent prices among the top ICT leaders in the world over the last two decades correlating with the effects of ICT, two faces of ICT advancement were identified.

On one side, advancement of ICT contributes to its prices increase by new functionality development, its dramatic advancement particularly centered by internet results in the decline of its prices through freebies, easy copying, and standardization.

It was demonstrated that the success of ICT leaders could largely be attributed to the way in which the two faces of ICT advancement were managed by maximizing the positive face of ICT advancement. This is done by means of the effective utilization of external resources in innovation while minimizing the negative face by outsourcing price decreasing factors.

All of the aforementioned points can be invaluable lessons for global sustainability in both ICT advanced and growing economies in the midst of the advancement of ICT. The significance of innovation-consumption co-emergence for harnessing the vigor of counterparts is discussed.
\end{abstract}

Keywords: Trap of ICT advancement, Two Faces of ICT, ICT Leaders, Anger of Consumer.

\section{INTRODUCTION}

While a dramatic advancement of information and communication technology (ICT) provides strong anticipation in significant economic growth, contrary to such anticipation, economic growth engine, particularly in ICT advanced economies has disappeared (except for Singapore) resulting in great stagnation (Cowen, 2011). This can be attributed to the two faced nature of ICT. While advancement of ICT contributes to increase its marginal productivity and subsequently its price by increasing new functionality development (Watanabe et al., 2003), the dramatic advancement of the Internet results in declining prices of ICT by freebies, easy copying and standardization (Watanabe et al., 2014).

Journal of Technology Management for Growing Economies

Vol. 5 No. 2

October 2014 pp. $49-71$

\section{ChITKARA 司 UNIVERSITY}

C 2014 by Chitkara University. All Rights Reserved. 
Watanabe, $\mathrm{C}$. Naveed, K. Zhao, W.
To date, significant numbers of analyses have demonstrated the impact of ICT advancement on socio-economic factors. Triggered by Nobel laureate Solow's "Productivity Paradox", which pointed out the discrepancy between measures of investment in ICT and measures of output at the national level by remarking "You can see the computer age everywhere but in the productivity statistics" (Solow, 1987), reactions demonstrating the significant role of ICT for the advancement of socio-economy were very few.

The first reaction to the production paradox was to try to explain why it might exist. These explanations were summarized by Brynjolfsson (1993) into four categories- (i) measurement errors of information technology (IT) capital due to rapid price and quality changes, and failure of economic statistics to measure qualitative improvements in the output of service industries; (ii) time lags, an argument made by David (1990) postulating that IT would not have a measureable impact on productivity until it reached a critical mass of diffusion and experience; (iii) management practices, which had not yet evolved to take advantage of the potential of the technology; and (iv) productivity in the whole economy.

The second reaction to the production paradox was to develop more sophisticated models to ease out the relationship between IT and productivity. Studies in 1990s by Brynjolfsson and Hitt (1996), and by Lichtenberg (1995) found evidence that refuted the productivity paradox at the firm level, showing that IT investment was strongly correlated with higher levels of output. In addition, at the country level, a study by Kraemer and Dedrick (1994) of AsiaPacific countries showed a significant relationship between IT spending and GDP growth. These studies were followed by additional studies at the firm and country level (Dedrick and Kraemer, 2001).

By the late 1990s there were some signs that productivity in the workplace had been improved by the introduction of IT, especially in the US. Brynjolfsson and Hitt (1998) found a significant positive relationship between IT investments and productivity, at least when these investments were made to complement organizational changes (Brynjolfsson and Hitt, 1998). It was considered that there was no paradox (Triplett, 1999).

Near to the end of the first decade of this century, a new paradox appeared to have emerged. IT industry executives astonished as to why business executives did not invest much more in IT than they usually did, given that IT returns were so large. This can largely be attributed to the third industrial revolution initiated by the dramatic advancement of the internet (Rifkin, 2011). Dramatic advancement of the internet has changed computer initiated IT world significantly. The Internet promotes more free culture, the consumption of which provides utility and happiness to people, but cannot be captured through

Journal of Technology Management for Growing Economies, Volume 5, Number 2, October 2014 
GDP figures that measure revenue (Lowrey, 2011). The democratization of manufacturing is being accompanied by the tumbling cost of marketing. Due of the centralized nature of the communication technologies of the first and second industrial revolutions initiated by newspapers, magazines, radio and TV marketing costs, it were high and favored giant firms, who could afford to devote substantial funds to market their products and services. The internet has transformed marketing from a significant expense to a negligible cost, allowing start-ups and small and medium size enterprises to market their goods and services on the internet sites that stretch over virtual space, enabling them to compete and even surpass many of the giant business enterprises of the $21^{\text {st }}$ century. Connecting multitudes of sellers and buyers in virtual space is almost free. By replacing all of the middlemen, from wholesalers to retailers, with a distributed virtual network of sellers and buyers and eliminating transaction costs that are marked up at every stage in the marketing process, US e-market place Etsy, for example, has created a new global craft bazaar that scales laterally rather than hierarchically, and markets goods collaboratively rather than topdown. Etsy brings another dimension to the market, the personalization of relationship between seller and buyer.

Dramatic advancement of the internet has changed the entire system interactive, integrated and seamless. This interconnectedness is creating completely new opportunities for cross-industry relationships. The third industrial revolution brings with it a new era of distributed capitalism in which millions of existing and new businesses and homeowners become energy players (Rifkin, 2011).

Such a dramatic advancement of the internet and subsequent third industrial revolution inevitably emerged as new paradox of the advancement of ICT. Brynjolfsson, who first reacted to Solow's production paradox in 1993 (Brynjolfsson, 1993) asked the question: "Could technology be destroying jobs?" (Brynjolfsson and McAfee, 2011). They then expanded further to explore whether advancing ICT might be an important contributor to the current unemployment disaster. They concluded that the root cause was not a decline in innovation but an acceleration of innovation. Technological advancement had moved so fast that many people were losing the race against the machine.

Cowen (2011) analyzed the similar problem. He argued that contrary to the dramatic advancement of the internet and subsequent ICT advancement, we were living through the consequence of a dramatic decrease in the rate of innovation. He argued that the consequence of slowing innovation was a fewer number of new industries and less creative destruction, hence new jobs.

These opposite beliefs can be reconciled more easily than is immediately apparent. Brynjolfsson and McAfee (2011) focus on the technology sector,

Journal of Technology Management for Growing Economies, Volume 5, Number 2, October 2014
Structural Source of the Trap of ICT 
Watanabe, $\mathrm{C}$. Naveed, K. Zhao, W. where it appears that innovation is happening more rapidly than ever. While Cowen (2011) looks at the entire economy and sees stagnation, or regression, in large sectors, such as health care, education, and government, indeed any sector that deals more with managing people than with managing things, the former being more complex and less conductive to innovation and job creation. As general innovation opportunities have slowed, business turn to the next activity with the highest return. Cutting costs by using technology advances to automate processes and eliminating the need to hire more workers to produce more output (Ogden, 2012). He suggested a possibility of the consequence of the two faced nature of ICT.

Notwithstanding such stimulating pioneering debates, particularly noteworthy suggestion of the two faced nature of ICT, none has ever demonstrated the impacts of the two faced nature of ICT in current great stagnation, particularly in ICT advanced economies (Watanabe et al., 2014).

In light of the significant consequence of the trap of the dramatic advancement of ICT in global economy both nations and firms that have been compelling their productivity decline resulting in the great stagnation in ICT advanced economies and therefore its structural sources were analyzed.

Based on an empirical analysis tracing the trend in marginal productivity of ICT and subsequently its prices in world ICT top leaders over the last two decades correlating with the effects of ICT, two faces of its advancement were identified.

The next section reviews trap of ICT advancement and its possible source. After this, the analytical framework is explained. Empirical analysis encompassing the source of the trap and its impacts is demonstrated in the section thereafter. Lastly, a brief summary of the noteworthy findings, policy implications supportive to resilient business and direction for future works are provided.

\section{TRAP OF ICT ADVANCEMENT AND ITS POSSIBLE SOURCE}

The advancement of ICT led ICT driven global economy resulted in bipolarization between ICT advanced economy and ICT growing economy in both nations and global ICT firms (Watanabe et al., 2014). Under such circumstances, certain R\&D matured resilient ICT firms manage to maintain sustainable growth while the majority of R\&D matured ICT firms suffer "the great stagnation" (Cowen, 2011) because of the trap of ICT advancement. Success in resilient ICT firms can largely be attributed to efficient functionality development by maximizing R\&D profitability (e.g., Apple) and open innovation (e.g., Canon) while minimizing the possibility of risk taking by restraining elasticity of such profitability (e.g., Apple) and depending on spillover effect (e.g., Canon) (Watanabe et al., 2014).

Given that these business models enable resilient firms to maintain sustainable growth despite the fatal nature of the great stagnation subsequent

Journal of Technology Management for Growing Economies, Volume 5, Number 2, October 2014 
to the high dependency on the dramatic advancement of the Internet with "freebies and easy copying" nature, following two faces as illustrated in Figure 1 can be postulated as a possible source of the trap of ICT advancement (Watanabe et al., 2014).
Structural Source of the Trap of ICT

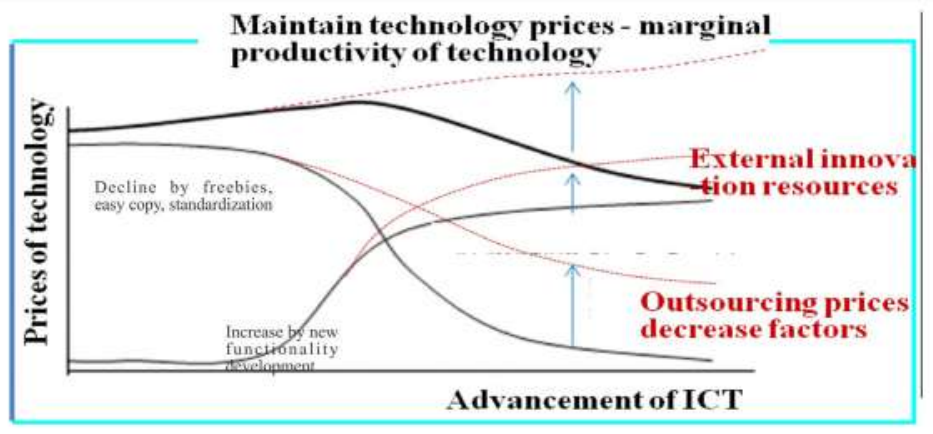

Figure 1: ICT's Identical Two Faces

Source: Author's Original.

Figure 1 illustrates ICT's identical two faces. Advancement of ICT generally contributes to enhanced prices of technology by increasing new functionality development. However, the dramatic advancement of the internet reacts to decline in the prices of technology due to its nature by freebies, easy copying and mass standardization. Consequently, prices of technology in highly R\&D intensive economies may move towards a declining trend resulting in a decreasing in their growth rate as outlined in Figure 2. This can be the structural source of the trap of ICT advancement compelling ICT advanced nations/firms suffering a vicious cycle between advancement of ICT and its marginal productivity ${ }^{1}$ decrease.

Production function and growth rate of ICT firms can be depicted as follows: Contribution by traditional factors technology (TFP) TFP

$$
Y=F(X, T) \quad \frac{\Delta Y}{Y}=\Sigma\left(\frac{\partial Y}{\partial X} \cdot \frac{X}{Y}\right) \frac{\Delta X}{X}+\left(\frac{\partial Y}{\partial T} \cdot \frac{T}{Y}\right) \frac{\Delta T}{T} \approx \Sigma\left(\frac{\partial Y}{\partial X} \cdot \frac{X}{Y}\right) \frac{\Delta X}{X}+\frac{\partial Y}{\partial T} \cdot \frac{R}{Y}
$$

Since $\frac{\partial Y}{\partial T}=\frac{p_{T}}{p_{Y}}, T F P=\frac{p_{T}}{p_{Y}} \cdot \frac{R}{Y}$

$$
\frac{p_{T}}{p_{Y}} \cdot \frac{R}{Y} \rightarrow p_{T} \text { decrease } \rightarrow \frac{\Delta Y}{Y} \text { decrease }
$$

$Y$ : production, $X$ : traditional production factors (labor, capital, materials and energy), $T$ : technology stock $(\Delta T \approx R), R$ : R\&D investment, $p_{T}, p_{S}$ : prices of technology and products

Figure 2: Scheme of the Great Stagnation due to the Decrease in Technology Prices. 
Watanabe, $\mathrm{C}$. Naveed, K. Zhao, W.

Given the foregoing circumstances, ICT firms endeavor should focus on accelerating price increase by means of successive efficient new functionality development while minimizing price decrease factors by outsourcing them to other parties.

Noteworthy accomplishments demonstrated by resilient global ICT firms (Watanabe et al., 2014) support this postulate and provide us constructive suggestions supportive to constructing a new business model satisfying both efficiency and resilience in a global competitive market.

These accomplishments suggest the following co-evolutionary acclimatization system that enables both ICT advanced and growing economies harness the vigor of counterparts. While R\&D matured ICT firms enable further advancement of ICT, it results in declining its productivity. Thus, such advancement should be addressed to the advancement of R\&D increasing ICT firms, which enjoy a virtuous cycle between its advancement and productivity increase leading to sustainable growth as reviewed in Figure 3 if its ICT advancement turns out to as an enabling position.

$$
\begin{array}{ll}
Y: \text { production, } X \text { : labor and capital, } T: \text { technology stock, } R \text { : R\&D expenditure, } \\
N \text { : carrying capacity of diffusion of } T, F D: \text { functionality development, } \\
\text { a: velocity of diffusion. }
\end{array}
$$

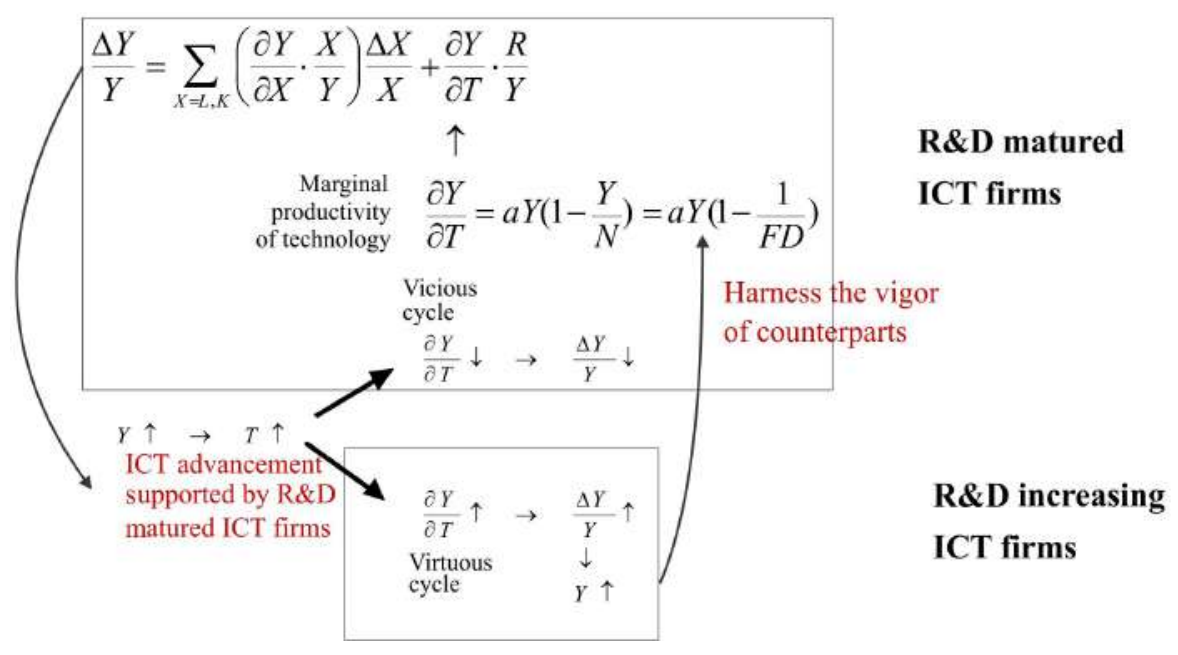

Figure 3: Scheme of Co-evolutionary Acclimatization in Global ICT Firms

\section{ANALYTICAL FRAMEWORK \\ ICT Prices}

Production function encompassing production factors contributing to GDP $(Y)$ as labor $(L)$, non-ICT capital services $(n-I C T)$, ICT capital services

Journal of Technology Management for Growing Economies, Volume 5, Number 2, October 2014 
(ICT), and other factors contributing to growth $\left(T_{r}\right)$ can be depicted as follows ${ }^{2}$ :

$$
Y=F\left(L, n-I C T, I C T, T_{r}\right)
$$

where ICT encompasses capital services provided by assets derived from the advancement of ICT and embodying into computer hardware and equipment, telecommunication equipment, and computer software and services, while $T_{r}$ accounts for the changes in output not caused by changes in other production factors ${ }^{3}$.

Contribution of ICT to GDP growth $\phi$ can be depicted as follows:

$$
\phi=\left(\frac{\partial Y}{\partial I} \cdot \frac{I}{Y}\right) \frac{\Delta I}{I}
$$

where $I$ denotes ICT and $\Delta I=\frac{d I}{d t}$

From equation (2), marginal productivity of ICT can be depicted as follows:

$$
\frac{\partial Y}{\partial I}=\frac{\phi}{\frac{I}{Y} \cdot \frac{\Delta I}{I}}
$$

This is equivalent to relative prices of ICT in the profit maximum behavior under the competitive circumstance as follows:

$$
\frac{\partial Y}{\partial I}=p_{I}=\frac{p_{I C T}}{p_{Y}}
$$

Therefore, prices of ICT can be measured by equations (3) and (4). All data consisting of these equations are available in the database indicated in the footnote 2 .

\section{Effects of ICT Advancement in Its Prices Change}

Given the ICT's identical two faces as illustrated in Figure 1, and prices increase by new functionality development is governed by ICT advancement as a whole in a logistic growth way. Price decline is initiated by the increase in the Internet dependency in a reverse logistic growth way (Watanabe et al., 2001), trajectory of ICT prices can be depicted by the following equation: 
Watanabe, C.

Naveed, K.

Zhao, W.

$$
p_{I}=\frac{N}{1+b_{i} e^{-a_{i} I}}+\frac{N}{1+b_{j} e^{a_{j} J}}
$$

where $J$ : dependency on the Internet, $N$ : carrying capacity ${ }^{4}, a_{i}, a_{j}$ and $b_{i}, b_{j}$ :diffusion velocity of $I$ and $J$, and initial stage of diffusion of $I$ and $J$, respectively. Equation (5) can be developed as follows:

$$
\begin{aligned}
& \frac{p_{I}}{N}=\frac{1+b_{j} e^{a_{j} J}+1+b_{i} e^{-a_{i} I}}{\left(1+b_{i} e^{-a_{i} I}\right)\left(1+b_{j} e^{a_{j} J}\right)}=\frac{2+b_{i} e^{a_{i} J}+b_{i} e^{-a_{i} I}}{1+b_{j} e^{a_{j} J}+b_{i} e^{-a_{i} I}+b_{i} b_{j} e^{-a_{i} I} e^{a_{j}, J}} \\
& \approx \frac{2+b_{j} e^{a_{j} J}+b_{i} e^{-a_{i} I}}{1+b_{i} b_{j}+b_{j} e^{a_{j} J}+b_{i} e^{-a_{i} l}}=1+\frac{1-b_{i} b_{j}}{1+b_{i} b_{j}+b_{j} e^{a_{j} J}+b_{i} e^{-a_{i} l}} \\
& \frac{p_{I}}{N}-1=\frac{1-b_{i} b_{j}}{1+b_{i} b_{j}+b_{j} e^{a_{i j} j}+b_{i} e^{-a_{i} I}} \\
& \frac{N}{N-p_{I}}=\frac{1}{1-\frac{p_{I}}{N}}=-\frac{1+b_{i} b_{i}}{1-b_{i} b_{j}}-\frac{b_{j} e^{a_{j} J}}{1-b_{i} b_{j}}-\frac{b_{i} e^{-a_{i} I}}{1-b_{i} b_{j}} \approx-\frac{1+b_{i} b_{i}}{1-b_{i} b_{j}}-\frac{b_{j}}{1-b_{i} b_{j}}\left(1+a_{j} J\right)-\frac{b_{i}}{1-b_{i} b_{j}}\left(1-a_{i} I\right) \\
& =-\frac{1+b_{i} b_{i}+b_{i}+b_{j}}{1-b_{i} b_{j}}-\frac{a_{j} b_{j}}{1-b_{i} b_{j}} J+\frac{a_{i} b_{i}}{1-b_{i} b_{j}} I \\
& \equiv \alpha+\beta J+\gamma I \\
& \text { where } \alpha=-\frac{1+b_{i} b_{i}+b_{i}+b_{i}}{1-b_{i} b_{j}}=-\frac{\left(1+b_{i}\right)\left(1+b_{j}\right)}{1-b_{i} b_{j}}, \quad \beta=-\frac{a_{i} b_{j}}{1-b_{i} b_{j}}, \quad \gamma=\frac{a_{i} b_{i}}{1-b_{i} b_{j}}
\end{aligned}
$$

\section{EMPIRICAL ANALYSIS}

\section{Two Faces of ICT Advancement}

\section{Factors Governing Prices of ICT}

Aiming at demonstrating the significant effects of two faced nature of ICT advancement which can be considered the main source declining the marginal productivity of ICT and subsequently its price decrease resulting in greater stagnation particularly in ICT advanced economies (Watanabe et al., 2014), an empirical analysis was attempted taking the world's ICT top leaders - Finland and Singapore.

Table 1 tabulates global ICT ranking in 2012 based on the state of the Networked Readiness Index (NRI $)^{5}$ published annually by the World Economic Forum. 
Table 1: Ranking of the Networked Readiness in 2012 (top 50 out of 144 countries)

\begin{tabular}{|l|l|l|l|}
\hline $\mathbf{1}$ Finland 5.98 (3) & 16 Luxembourg 5.37 (21) & 31 Saudi Arabia 4.82 (34) & 46 Panama 4.22 (57) \\
2 Singapore 5.96 (2) & 17 Iceland 5.31 (15) & 32 Lithuania 4.72 (31) & 47 Jordan 4.20 (47) \\
3 Sweden 5.91 (1) & 18 Australia 5.26 (17) & 33 Portugal 4.67 (33) & 48 Montenegro 4.20 (46) \\
4 Netherlands 5.81 (6) & 19 Austria 5.25 (19) & 34 Chile 4.59 (39) & 49 Poland 4.19 (49) \\
5 Norway 5.66 (7) & 20 New Zealand 5.25 (14) & 35 Cyprus 4.59 (32) & 50 Italy 4.18 (48) \\
6 Switzerland 5.66 (5) & 21 Japan 5.24 (18) & 36 Puerto Rico 4.55 (36) & \\
7 United Kingdom 5.64 (10) & 22 Estonia 5.12(24) & 37 Slovenia 4.53 (37) & \\
8 Denmark 5.58 (4) & 23 Qatar 5.10 (28) & 38 Spain 4.51 (38) & \\
9 United States 5.57 (8) & 24 Belgium 5.10 (22) & 39 Barbados 4.49 (35) & \\
10 Taiwan, China 5.47 (11) & 25 UAE 5.07 (30) & 40 Oman 4.48 (40) & \\
11 Korea, Rep. 5.46 (12) & 26 France 5.06 (23) & 41 Latvia 4.43 (41) & \\
12 Canada 5.44 (9) & 27 Ireland 5.05 (25) & 42 Czech Republic 4.38 (42) & \\
13 Germany 5.43 (16) & 28 Malta 4.90 (26) & 43 Kazakhstan 4.32 (55) & \\
14 Hong Kong SAR 5.40 (13) & 29 Bahrain 4.83 (27) & 44 Hungary 4.29 (43) & \\
15 Israel 5.39 (20) & 30 Malaysia 4.82 (29) & 45 Turkey 4.22 (52) & \\
\hline
\end{tabular}

Source: The Global Information Technology Report 2013 (World Economic Forum, 2013).

${ }^{a}$ Ranking indicates the state in 2012 while the state in 2011 is indicated in parenthesis. ${ }^{b}$ Figure demonstrates the score of the Networked Readiness Index 2013 (the level in 2012).

Table 1 demonstrates that Finland and Singapore play leading role in the state of the advancement (development and effective utilization) of ICT and are the world's ICT top leaders.

Focusing on the ICT driven development trajectory in Finland and Singapore over the period 1994 and 2011, trends in prices of ICT were computed by utilizing equations (3) and (4).

Figure 4 demonstrates the result of the computation through index $(1990=$ $100)$ based ICT intensity $(I / Y)$. Looking at the figure, we note that while prices of Finland steadily increased during 1994-1999, they turned out to declining trend from 2000. While they maintained a plateau state with slight up and down during 2001-2008, they changed to dramatic decline after the Lehman shock in 2008. While prices of ICT in Singapore demonstrated conspicuously high level in 1994-1997 with slight up and down as a general nature of the "Asian Tiger" (newly emerged economy), they changed to dramatic decline after the Asian financial crisis in 1997. Such a dramatic decline calmed down in 2001 and changed to slightly decreasing trend with certain up and down accessing to the similar level in Finland.

Dramatic declining trend in Singapore in the late 1990s can be considered as a consequence of the transition from newly emerged economy to developed economy together with the Asian financial crisis in 1997. A notable decline in the latter part of the first decade of this century to the beginning of the second
Structural Source of the Trap of ICT 
Watanabe, $\mathrm{C}$. Naveed, K. Zhao, W.

decade can be considered as a consequence of "the great stagnation" postulated by Cowen (2011).

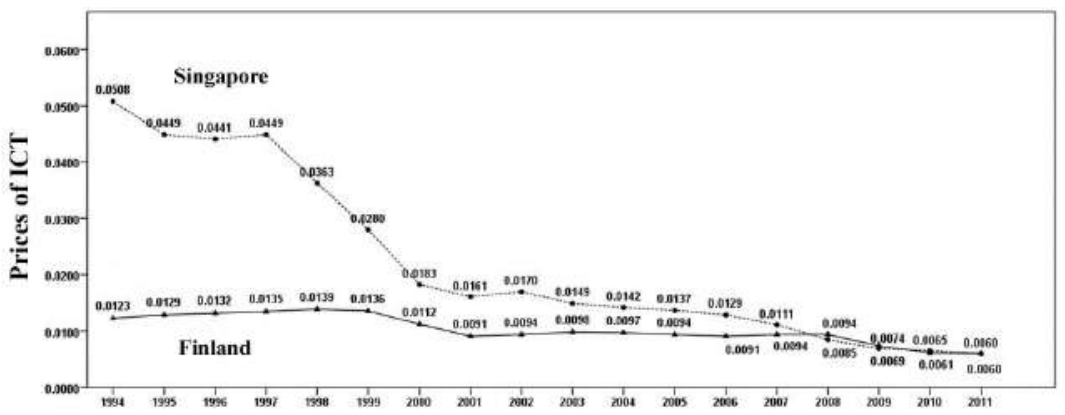

Figure 4: Trends in the Prices of ICT in ICT Top Leaders: Finland and Singapore (1994-2011).

${ }^{a}$ Prices of ICT (relative prices of ICT) are computed by the following equation: $p_{I}=\frac{\phi}{\frac{I}{Y} \cdot \frac{\Delta I}{I}}$ where $\phi:$ contribution of ICT to GDP growth (\%: equation (2)), $\frac{\Delta I}{I}$ : growth rate of ICT capital services (\%), and $\frac{I}{Y}$ : ICT intensity (ratio of ICT and
GDP) using index $(1990=100)$. In order to demonstrate Cohen's hypothetical view, particularly two-faced nature of ICT resulting in declining the prices of ICT, effects of ICT advancement both of general increase in ICT stock as a whole and increase in the dependency on the Internet on the ICT prices change were next analyzed.

Figure 5 illustrates trends in ICT stock in Finland and Singapore over the period 1990-2011. Looking at the figure we note that ICT stock in both countries demonstrated steady increase with higher increase rate in Finland.

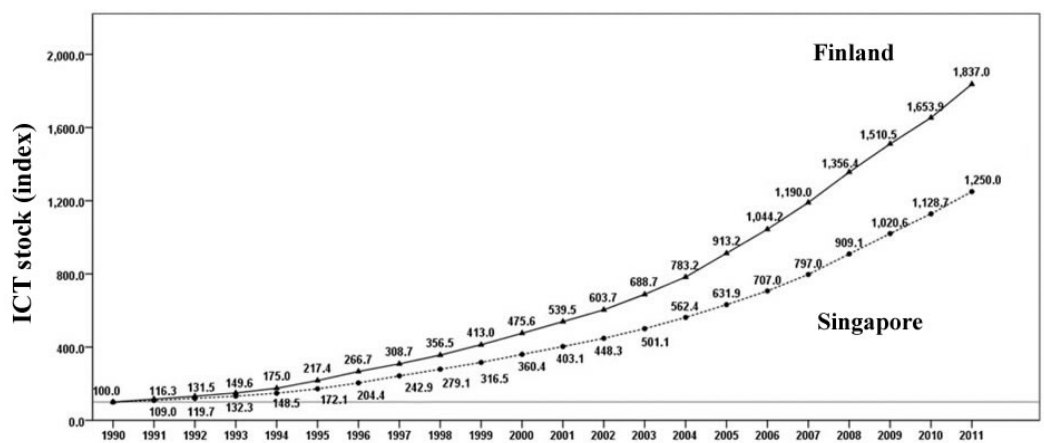

Figure 5: Trends in ICT Stock in ICT Top Leaders: Finland and Singapore (1990-2011) Index: $1990=100$.

Source: The Conference Board Total Economy Database ${ }^{T M}$, January 2013, http://www. conference-board.org/data/economydatabase/

Journal of Technology Management for Growing Economies, Volume 5, Number 2, October 2014 
Similarly, Figure 6 illustrates trends in the Internet dependency in Finland and Singapore over the period 1990-2011.

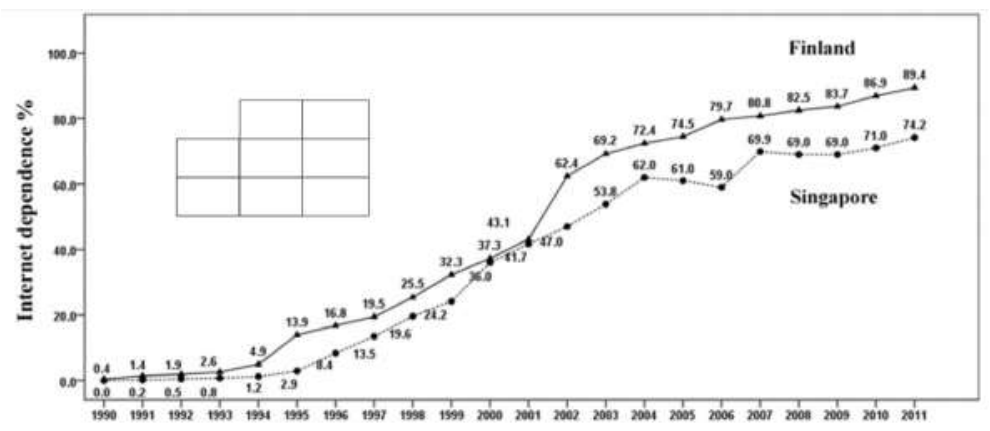

Structural Source of the Trap of ICT

Figure 6: Trends in the Internet Dependency in ICT Top Leaders: Finland and Singapore (1990-2011).

Source: World Telecommunication/ICT Indicators Database (UN, 2013).

Figure 6 demonstrates consequently high increase rate in the Internet dependency in ICT top leaders in 1994-2000 particularly in Singapore while it changed to low increase rate in 2001-2011.

\section{Two Faced Nature of ICT}

Based on the foregoing analyses and observations and equation (6), effects of ICT stock and dependency on the internet on the changes in ICT prices in ICT top leaders were analyzed. Figs. $\mathbf{7}$ and $\mathbf{8}$ together with the regression results demonstrate the results of the analyses in decomposing the trends in the prices of ICT into ICT driven logistic growth trajectory $(I)$ and the dependency on internet is attributable to reverse logistic growth trajectory $(J)$.

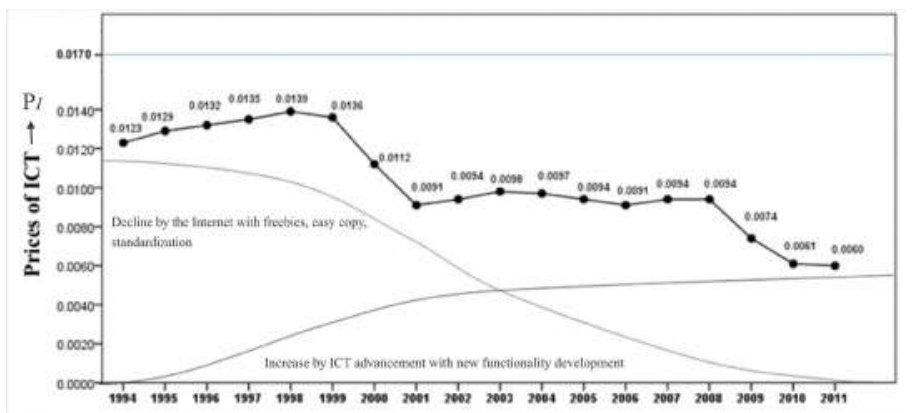

Figure 7: Trends in the Effects of ICT Advancement and Increase in the

Internet Dependency to ICT Prices in Finland (1994-2011).

$$
\begin{aligned}
& \frac{1}{1-\frac{p_{I}}{N}}=3.060+0.081 D_{1} J-0.026 D_{2} J-0.070 D_{3} J+0.001 I+0.632 D_{2}+3.747 D_{3}-0.797 D \text { adj. } R^{2} 0.992 \\
& (23.67 *)\left(11.92^{*}\right) \quad\left(-4.82^{*}\right) \quad\left(-2.12^{* *}\right)\left(1.89^{* *}\right)\left(2.28^{* *}\right)\left(1.40^{* * *}\right)(-6.89 *) \text { DW } 24.43
\end{aligned}
$$


Watanabe, $\mathrm{C}$. Naveed, K. Zhao, W.
$\mathrm{P}_{I}$ : prices of ICT, $N$ : carrying capacity $(N=0.017), J$ : Internet dependency, $I$ : ICT advancement

\section{Dindicatesdummyvariables}

$D_{1}: 1994-1999=1$, other years $=0 ; D_{2}: 2000-2008=1 ; D_{3}: 2009-2011=1 ; D: 1999,2001=1$

Figures in parenthesis indicate t-statistics (significant at the $* 1 \%, * * 5 \%,{ }^{*} * * 10 \%$ level, respectively).

Looking at Figure 7 together with the regression results, we note that the steady increase in ICT prices in Finland in 1994-1999 can be attributed to the advancement of ICT with new functionality development, while their declining trend from 2000 can largely be attributed to the dramatic advancement of the internet and subsequent increasing popularity of freebies, easy copy and standardization nature. Notwithstanding such effects, Finland maintained its ICT prices in plateau state with slight ups and downs during 2001-2008. This can be attributed to the consistent increase in its ICT stock as demonstrated in Figure 5 and subsequent increase in new functionality development. Dramatic decline in the ICT prices after 2008 can be attributed to the stagnation of the increased efforts ICT under the global simultaneous stagnation due to the Lehman shock in 2008. Dramatic increase in price declining feature of the internet corresponding to this period accelerated to such a decline.

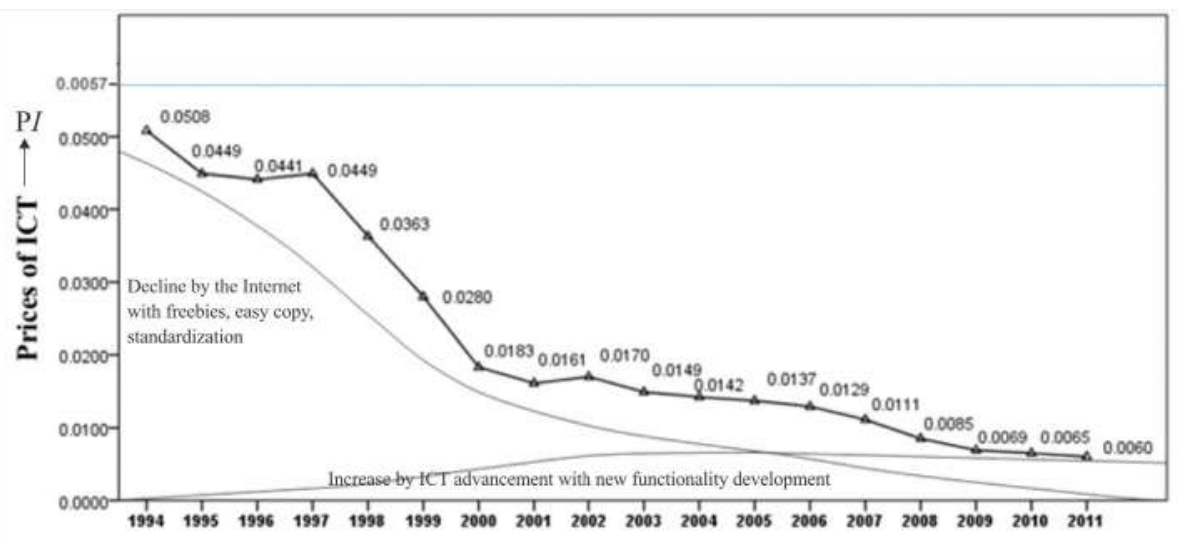

Figure 8: Trends in the Effects of ICT Advancement and Increase in the Internet Dependency to ICT Prices in Singapore (1994-2011).

$$
\begin{aligned}
\frac{1}{1-\frac{p_{l}}{N}}=36.454-0.448 D_{1} J-1.081 D_{2} J+0.167 I-43.797 D_{1}+15.056 D & \text { adj } R^{2} 0 . \\
& \left(2.42^{* *}\right)\left(-1.92^{* * *}\right) \quad\left(-2.81^{* *}\right) \quad\left(11.73^{*}\right)\left(-2.573^{* *}\right)\left(2.88^{* *}\right) \text { DW } 1.51
\end{aligned}
$$

$\mathrm{P}_{I}$ : prices of ICT, $N$ : carrying capacity $(N=0.057), J$ : Internet dependency, $I$ : ICT advancement

Journal of Technology Management for Growing Economies, Volume 5, Number 2, October 2014 
Dindicates dummyvariables

$D_{1}: 1994-2000=1$, other years $=0 ; D_{2}: 2001-2011=1 ; D: 2000,2009=1$

Figures in parenthesis indicate t-statistics (significant at the $* 1 \%, * * 5 \%$, $* * * 10 \%$ level, respectively).

Similarly, looking at Figure 8 together with the regression results we note that while advancement of ICT maintained steady increase in ICT prices in Singapore, increase in the internet dependency changed due to decline in the prices. As reviewed earlier, dramatic decline in conspicuously high level of Singapore's ICT prices in the late 1990s can be considered as a consequence of the transition from newly emerged economy to developed economy together with the Asian financial crisis in 1997. While such a dramatic decline calmed down in 2001 and changed to slightly decreasing trend with certain ups and downs. This can be attributed to the balance between the positive effects of ICT advancement and the negative effects of the internet dependency. Notable decline in the latter part of the first decade of this century to the beginning of the second decade can be attributed to the similar sources as Finland: global simultaneous stagnation and dramatic increase in price declining feature of the internet.

\section{New Paradox of Productivity}

\section{Increasing Trend in Un-captured GDP}

These results support the hypothesis that ICT's identical two faces would be the structural source of the trap of ICT advancement emerging new paradox of productivity as in the reviewed earlier sections. Advances in ICT can largely be attributed to dramatic advancement of the internet, which has significantly changed the computer initiated IT world. The internet promotes a more free culture, the consumption of which provides utility and happiness to people but cannot be captured through GDP figures that measures revenue (Lowrey, 2011).

This un-captured GDP has become the major source of consumer's utility (happiness in consumption) and general happiness (JCO, 2012). This trend corresponds to a general shift in consumers preference from economic functionality (captured by GDP) to supra-functionality beyond economic value encompassing social, cultural, aspirational, tribal and emotional values (not necessarily captured by GDP) (Watanabe et al., 2011). The discrepancy between "captured GDP" and "un-captured GDP" incorporates significant implications, which are as follows-.

(i) First, there exists a possible hypothetical view that a decrease in ICT prices could be in line with a consumer preference shift from economic functionality to supra-functionality beyond economic value.

(ii) Second, shifting from "captured GDP" to "un-captured GDP" could
Structural Source of the Trap of ICT 
Watanabe, $\mathrm{C}$. Naveed, K. Zhao, W. correspond to the transfer of production efforts. Traditionally, all production efforts have been attributed to producer motivation as they can in turn obtain a compensating return. However, certain production efforts, particularly in cerebration, idealization and learning extraction efforts have been transferred from producers to consumers, which justify freebies to both producers and consumers 6 .

(iii) Third, under such shifting and transferring circumstances, conflict emerges in the transition leading to growing anger of consumers (Watanabe, 2013).

Figure 9 illustrates this transition dynamism. Elucidation of this transition in dynamism will be a crucial subject for resilience, which inevitably highlights the significance of analysis of consumer anger, which leads to innovation-consumption co-emergence.

\section{Advancement of ICT}

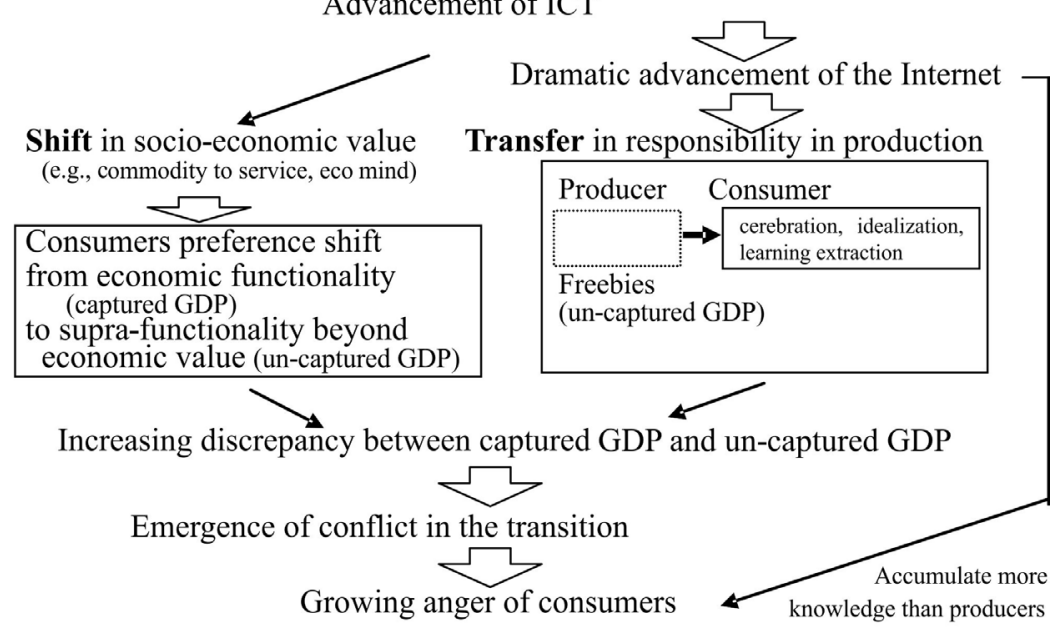

Figure 9: Transition Dynamism in New Paradox of Productivity and its Impact on Consumers

\section{Growing anger of consumers}

Since consumption shares more than $60 \%$ of GDP, its sustainable growth beyond anticipation issues would be crucial. However, contrary to such anticipation, it has been strongly warned that the increasing consumption haters among Japanese consumers, particularly among young generations have been increasingdue to non-existence of goods and services corresponding to their sincere requirement (Matsuda, 2010, 2012, Watanabe et al., 2012). This demonstrates protest to producers, which cannot satisfy their requirement in the foregoing transition. At the same time, they are irritating themselves being unable to produce their desiring goods and services by themselves. Accumulation of more knowledge 
than producers depending on the advancement of the internet accelerates such protest resulting in growing anger of consumers.

Given that, resilience incorporates assimilation, the capacity for using a shock as a trigger for renewal and improvement (Ilmola et al., 2013), this consumer's anger can be transformed into a springboard for new innovation. This anticipation prompts us a significance of innovation-consumption coemergence, which corresponds to co-evolutionary acclimatization as illustrated in Figure 3 suggesting to harness the vigor of hidden counterparts i.e., consumers.

Foregoing emerging conflict in the transition revealed explicitly through decline in marginal productivity of ICT and subsequently its price decrease provides significant impacts on its users by growing their angers to producers and also to themselves as being 'remained consumers' as illustrated in Figure 10 (Watanabe, 2013).

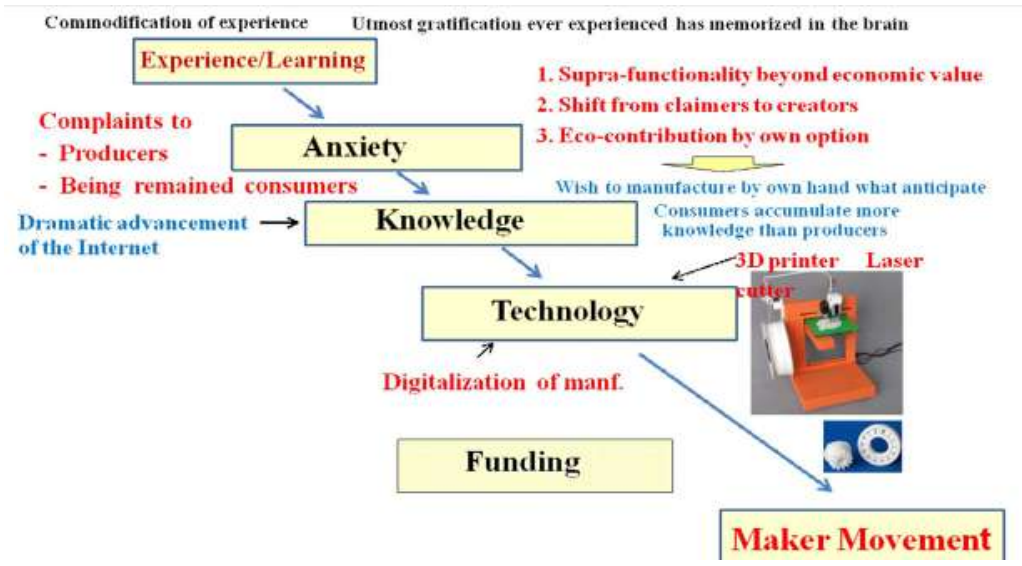

Figure 10: Growing Anger of Consumers

\section{Shift to a Post-excessive Consumption Society}

\section{Declining Trend in Marginal Propensity to Consume}

Global simultaneous stagnation triggered by the US oriented sub-prime loan issues in 2007 and subsequent Lehman shock in 2008 has reminded us of a possibility of a post-excessive consumption society. Table 2 summarizes correlation between GDP $(Y)$ and household final consumption expenditure $(C)$ in 6 countries including ICT top leaders, Finland and Singapore over the period 1990-2012. Looking at the table we note that their coefficients have changed to declining trend from 2007 (US and Germany) or 2008 (Finland, Singapore, Japan and UK) corresponding to sub-prime loan issue and subsequent Lehman shock. Since this coefficient depicts marginal propensity of consume $\left(\frac{\partial C}{\partial V}\right)$, Table 2 suggests that marginal propensity of consumption in these countries 
Watanabe, $\mathrm{C}$. Naveed, K. Zhao, W.

64

changed to a declining trend after the global simultaneous stagnation which is demonstrated in Table 3.

Foregoing observation supports a possibility of the emergence of postexcessive consumption society (Matsuda, 2010, 2012) in which consumer's increasing initiative in innovation game is anticipated (McDonagh, 2008, Watanabe, 2009, Watanabe et al., 2011). Such an increasing initiative by the consumers accelerates a shift of their preference from economic functionality to supra-functionality beyond economic value encompassing social, cultural, aspirational, tribal and emotional value (Watson and McDonagh, 2004; McDonagh, 2008; Watanabe, 2009).

Table 2: Correlation between GDP and Final Consumption in Selected 6 Countries (1990-2012)

\section{Finland}

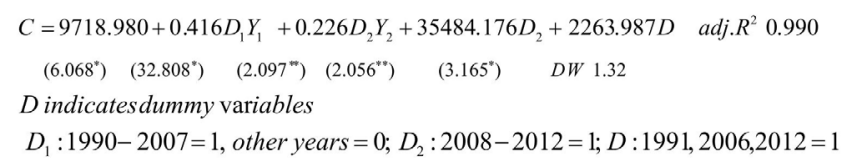

\section{Singapore}

$$
\begin{aligned}
& C=42293.395+0.317 D_{1} Y_{1}+0.213 D_{2} Y_{2}-37093.567 D_{1}+6700.379 D \text { adj. } R^{2} 0.986
\end{aligned}
$$

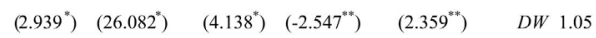

\section{Japan}

$$
\begin{aligned}
& C=120152469.362+0.591 D_{1} Y_{1}+0.340 D_{2} Y_{2}-131023751.720 D_{1}-7145417.823 D \text { adj } R^{2} 0.978 \\
& \begin{array}{lllll}
\left(1.87^{* *}\right) & \left(25.12^{*}\right) & \left(2.68^{* *}\right) & \left(-2.02^{* * *}\right) & \left(-4.12^{*}\right)
\end{array} \text { DW } 1.41
\end{aligned}
$$

\section{USA}

$$
\begin{aligned}
& C=-656297.750+0.735 D_{1} Y_{1}+0.641 D_{2} Y_{2}+1253670.120 D_{2}-138390.806 D \text { adj } R^{2} 0.999
\end{aligned}
$$

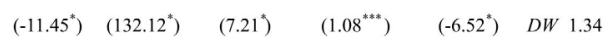

$$
\begin{aligned}
& D \text { indicatesdummy variables } \\
& D_{1}: 1990-2006=1 \text {, other years }=0 ; D_{2}: 2007-2011=1 ; D: 1997,1998,1999,2000=1
\end{aligned}
$$

\section{Germany}

$$
\begin{aligned}
& C=48320.565+0.549 D_{1} Y_{1}+0.442 D_{2} Y_{2}+200373.730 D_{2}-33538.105 D \text { adj. } R^{2} 0.990 \\
& \begin{array}{lllll}
\left(1.50^{* * *}\right) & \left(33.44^{*}\right) & \left(12.01^{*}\right) & \left(2.14^{* *}\right) & \left(4.91^{*}\right)
\end{array} \\
& D \text { indicates dummy variables } \\
& D_{1}: 1990-2006=1 \text {, other years }=0 ; D_{2}: 2007-2012=1 ; D: 2006,2007,2008=1 \\
& \mathbf{U} \mathbf{K} \\
& C=-121860.377+0.706 D_{1} Y_{1}+0.372 D_{2} Y_{2}+458633.357 D_{2} \quad \text { adj. } R^{2} 0.995 \\
& \left(-8.63^{*}\right) \quad\left(58.05^{*}\right) \quad\left(1.70^{* * *}\right) \quad\left(1.46^{* * *}\right) \quad \text { DW } 1.00 \\
& \text { D indicates dummy variables } \\
& D_{1}: 1990-2007=1 \text {, other years }=0 ; D_{2}: 2008-2012=1 \text {; }
\end{aligned}
$$

Journal of Technology Management for Growing Economies, Volume 5, Number 2, October 2014 
$C$ : Household final consumption expenditure, $Y$ : GDP

(Finland: Euro, Million, base year 2000; Singapore: Singapore Dollars, Million, base year 2005; Japan: Yen, Million, base year 2005; USA: US Dollars Million, base year 2005; Germany: Euro Million, base year 2000; UK: Pound Sterling Million, base year 2009)

Figures in parenthesis indicate t-statistics (significant at the $* 1 \%, * * 5 \%, * * * 10 \%$ level, respectively).

Source: National Accounts Official Country Data (United Nations Statistics Division, annual issues).

Table 3: Marginal Propensity to Consume in Selected 6 Countries

\begin{tabular}{|l|c|c|}
\hline & $1990-2007^{*}$ & $2008-2012^{* *}$ \\
\hline Finland & 0.42 & 0.23 \\
\hline Singapore & 0.32 & 0.21 \\
\hline Japan & 0.59 & 0.34 \\
\hline USA & 0.74 & 0.64 \\
\hline Germany & 0.55 & 0.44 \\
\hline UK & 0.70 & 0.37 \\
\hline
\end{tabular}

* 1990-2006 in US and Germany

** 2007-2012 in US and Germany

\section{Shift of Consumers Preferences}

As postulated by Nobel laureate in Economics, Modigliani, people never forget utmost gratification of consumption ever experienced that has memorized in the brain and affects consumer's preference in consumption (Modigliani, 1965). Such experience can be subject to socio-economic paradigm. As a consequence of historical change in nation's experiences, in line with the general shift in commodity oriented society to service and information oriented society, it is generally postulated that consumer's preference has been steadily shifting from economic functionality driven preference to supra-functionality beyond economic value driven preference (McDonagh, 2008; JCO, 2012). Here supra-functionality beyond economic value encompasses social, cultural, aspirational, tribal and emotional values. Such a shift can be observed clearly by "Public Opinion Survey Concerning People's Lifestyles," conducted annually by Japan's Cabinet Office (JCO) as illustrated in Figure. 11.

Journal of Technology Management for Growing Economies, Volume 5, Number 2, October 2014 
Watanabe, $\mathrm{C}$.

Naveed, K.

Zhao, W.

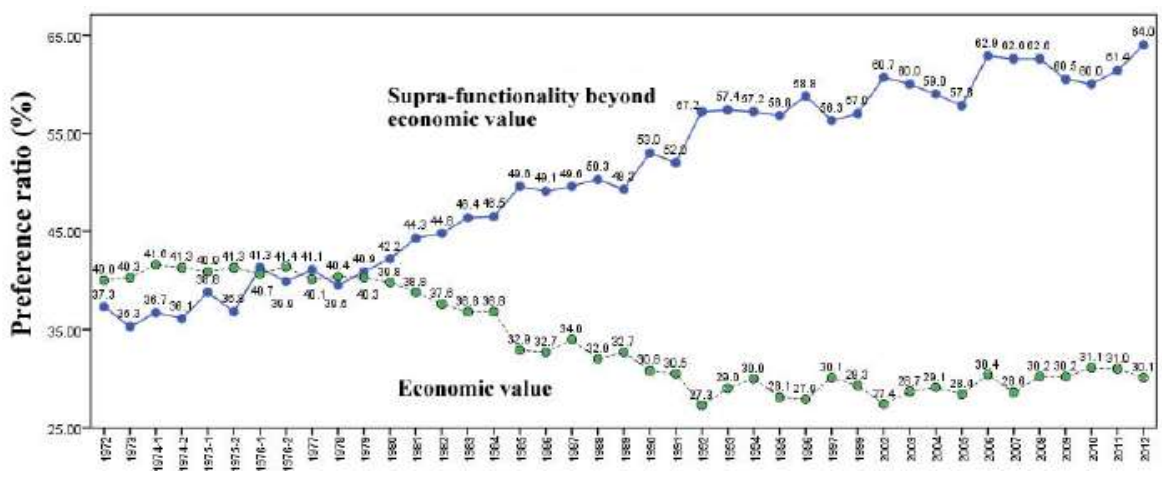

Figure 11: Trend in the Shift in Japanese Nation's Preferences (1972-2012).

* Not necessarily recorded every year and for few years it's recorded more than once.

Source: National Survey of Lifestyle Preferences (Japan Cabinet Office, annual issues).

Under such circumstances consumers desires have been shifting (i) from economic value to supra-functionality beyond economic value, (ii) from claimers to creators, and (iii) to eco-contribution by own option. Consequently, consumers complain to producers and also to themselves as being remained consumers have been growing. In parallel with such increase, consumers wish to manufacture by own hand what they anticipate has dramatically increased. Dramatic advancement of the internet has enabled consumer accumulate more knowledge than producers. Their consumption mode has changed to AISCEAS:

Attention $\rightarrow$ Interest $\rightarrow$ Search $\rightarrow$ Comparison $\rightarrow$ Examination $\rightarrow$ Action $\rightarrow$ Share

Maker movement enabled by digitalization of manufacturing, advancement of $3 \mathrm{D}$ printers and laser cutter has accelerated the foregoing change in consumer's preference and subsequent consuming style and behavior. New stream of emerging economies also affecting consumer's growing anger by realizing them the beauty of frugality and also suppliers simultaneously start up in new sales. Furthermore, increasing publicity of crowd funding enables consumer's start-up for manufacturing by themselves.

Foregoing observation supports a possibility of the emergence of a postexcessive consumption society (Matsuda, 2010, 2012) in which consumer's increasing initiative in innovation game is anticipated (McDonagh, 2008; Watanabe, 2009; Watanabe et al., 2011). Such an increasing consumer's initiative accelerates a shift of their preference from economic functionality to supra-functionality beyond economic value encompassing social, cultural, aspirational, tribal and emotional value (Watson and McDonagh, 2004;

Journal of Technology Management for Growing Economies, Volume 5, Number 2, October 2014 
McDonagh, 2008; Watanabe, 2009).

\section{CONCLUSION}

In light of the significant consequence of the trap of the dramatic advancement of information and communication technology (ICT) in global economy both nations and firms that have been compelling their productivity decline resulting in the great stagnation in ICT advanced economies, its structural sources were analyzed.

On the basis of an empirical analysis tracing the trend in marginal productivity of ICT and subsequently its prices in world ICT top leaders viz., Finland and Singapore over the last two decades correlating with the advancement of ICT and dependency of the internet. Two faces of ICT advancement were identified and their impacts on ICT users were analyzed.

Noteworthy findings include:

(i) Marginal productivity of ICT and subsequently its prices in world ICT top leaders viz., Finland and Singapore demonstrated a declining trend from this century.

(ii) While they were maintaining relatively plateaued state with slight ups and downs in this century, they changed to notable decline in the latter part of the first decade of this century.

(iii) While advancement of ICT contributes to its price increase by new functionality development, its dramatic advancement particularly centered by the internet resulted in its price decline by freebies, easy copying and standardization.

(iv) Sources of the recent notable decline can be attributed to the stagnation of ICT increase efforts under the global simultaneous stagnation due to the Lehman shock in 2008 as well as dramatic increase in price declining feature of the internet corresponding to this period.

(v) These decline in marginal productivity of ICT and subsequently its price decrease have provided significant impacts on its users by growing their angers to producers and also to themselves as being remained consumers.

(vi) Declining trend in marginal propensity to consume has led to sluggish consumption and subsequent economic stagnation resulting in a vicious cycle between them.

(vii) Such a trend together with general shift in consumer's preference from economic functionality to supra-functionality beyond economic value

Journal of Technology Management for Growing Economies, Volume 5, Number 2, October 2014
Structural Source of the Trap

of ICT 
Watanabe, $\mathrm{C}$. Naveed, K. Zhao, W. suggested a possibility of the emergence of post-excessive consumption society.

These findings provide the following policy suggestions:

(i) Two faced nature of ICT, particularly the price decreasing feature of the advancement of the internet should be seriously taken into account for resilient business.

(ii) Given that freebies, easy copying and standardization are possible sources compelling the price decrease by depending on the internet, transferring dynamism of corresponding values should be traced.

(iii) Provided that supra-functionality beyond economic value plays a governing role for consumers, similar transferring dynamism of encompassed values should be traced.

(iv) Relationship between foregoing two noting stream should be analyzed.

(v) ICT's new face, which is elastic enough to correspond to suprafunctionality beyond economic value, should be analyzed.

(vi) In this context, strategy for innovation-consumption co-emergence should be developed on a priority basis.

(vii) While a way to appease consumers growing anger may provide a constructive suggestion to this co-emergence, given that this anger remains intangible, the way to conceptualize voiceless voice of consumer's anger should be taken seriously.

Points of future works are summarized as follows:

(i) In order to generalize the foregoing findings and policy suggestions, analyses of additional countries are expected to be conducted.

(ii) Comparative analysis of institutional factors governing the ICT price trajectory and their attributing ICT advancement and dependency on the internet should be conducted.

(iii) Interdisciplinary approach exploring a way to analyze innovationconsumption co-emergence should be attempted by integrating economics, psychophysiology and engineering.

\section{ENDNOTES}

1. Given that the firms seek to profit maximum in the competitive market, marginal productivity of technology corresponds to relative price of technology (ratio of technology prices and prices of product).

2. This production function concept and subsequent data for the analysis are 
based on "The Conference Board Total Economy DatabaseTM, January 2013, http://www.conference-board.org/data/economydatabase/

3. While in the production function in Figs. 2 and 3 all stock of technological advancement including ICT capital services (excluding those services by obsolescent ICT) are treated by technology stock $T$, in the production function depicted by equation (1), with the aim to identify the identical contribution of ICT, ICT is treated independently by extracting from T in Figs. 2 and 3. Technology stock $\mathrm{T}_{r}$ in equation (1) accounts for the changes in output not caused by changes in other production factors including ICT and obsolescent ICT is categorized in $n$-ICT.

4. Since the Internet has been playing a leading role in the whole ICT and providing significant impacts on the diffusion trajectory of ICT, carrying capacity of logistic growth in $I$ and reverse logistic growth in $J$ as well as

their diffusion tempo $\left(a_{i} I\right.$ and $\left.a_{i} J\right)$ were treated as behaved in the similar way.

5. NRI can be used as a proxy of nation's ICT advancement which consists of Environment (Political and regulatory environment, Business and innovation environment), Readiness (Infrastructure and digital content, Affordability), Usage (Individual usage, Business usage, Government usage), and Impact (Economic impact, Social impact).

6. This is natural to producers as they depend certain due efforts on consumers efforts while consumers have not explicitly realized their contribution.

\section{REFERENCES}

Brynjolfsson, E. (1993) 'Productivity Paradox of Information Technology.', Communications of the Association for Computing Machinery, 36:12, pp. 66-77.

Brynjolfsson, E. and Hitt, L. (1996) 'Paradox Lost? Firm-level Evidence on the Returns to Information Systems Spending' ,Management Science, 42:4, pp. 541-558.

Brynjolfsson, E. and Hitt, L. (1998) 'Beyond the Productivity Paradox: Computers are the Catalyst for Bigger Changes', Communications of the Association for Computing Machinery, 41:8, pp. 49-55.

Brynjolfsson, E. and McAfee, A. (2011) 'Race against the Machine: How the Digital Revolution is Accelerating Innovation, Driving Productivity, and Irreversibly Transforming Employment and Economy', New York. Digital Frontier Press.

Cowen, T. (2011) 'The Great Stagnation', New York. Dutton.

David, P.A. (1990) 'The Dynamo and the Computer: A Historical Perspective on the Productivity Paradox.', American Economic Review, Papers and Proceedings, 80:2, pp. 355-361.

Dedric, J. and Kraemer, K. (2001) 'The Productivity Paradox: Is It Rosolved? Is There a New One? What Does It All Mean for Managers?', CRITO Consortium Advisory Board Panel: The End of the Productivity Paradox?, pp. 2-12.

Ilmola, L. and Casti, J. (2013) 'Seven Shocks and Finland', Innovation and Supply Chain Management, 7:3, pp. 112-124.

Japan's Cabinet Office (JCO) (2012) National Survey of Lifestyle Preferences, JCO, Tokyo.
Structural Source of the Trap of ICT 
Watanabe, $\mathrm{C}$. Naveed, K. Zhao, W.
Kraemer, K.L. and Dedrick, J. (1994) 'Payoffs from Investment in Information Technology: Lessons from the Asia-Pacific Region', World Development, 22: 12, pp. 1921-1931.

Lichtenberg, F.R. (1995) 'The Output Contributions of Computer Equipment and Personnel: A Firm Level Analysis.' Economic Innovations and New Technology, 3:3-4, pp. 201-218.

Lowrey, A.( 2011) Impacts of the Great Stagnation, New York Times.

Matsuda, H. (2010) 'Why not Buy, How to Purchase', Tokyo, Asahi-shimbun.

Matsuda, H. (2012) 'Extricating from Stagnation as a Consequence of Consumption Hating', Tokyo, PHP Institute.

McDonagh, D. (2008) 'Satisfying Needs beyond the Functional: The Changing Needs of the Silver Market Consumer', Proceedings of the International Symposium on the Silver Market Phenomenon - Business Opportunities and Responsibilities in the Aging Society, Tokyo.

Ministry of Internal Affairs and Communication (MIC) (2012)White Paper on Japan's Information and Communication Technology. MIC, Tokyo.

Modigliami, T .(1965) 'Life Cycle Hypothesis of Savings, the Demand for Wealth and Supply of Capital'Paper Presented at the Rome Congress of Econometric Society.

National Accounts Official Country Data (United Nations Statistics Division, annual issues).

Ogden, T.(2012) 'The Race vs. the Stagnation', Stanford Social Innovation Review, Spring.

Rifkin, J. (2011) 'The Third Industrial Revolution: How Lateral Power is Transforming Energy, the Economy, and the World', New York, Palgrave Macmillan.

Rifkin, J. (2013) 'The Third Industrial Revolution: How the Internet, Green Electricity, and 3-D Printing are Ushering in a Sustainable Era of a Distributed Capitalism', The World Financial Review.

Solow, R. (1987) 'We'd better Watch Out: The Myth of the Post-industrial Economy', New York Times Book Review 36.

The Conference Board Total Economy DatabaseT (2013) (online) (Available from) <URL:http:// www.conference-board.org/data/economydatabase/>.

Triplett, J.E. (1999) 'The Solow Productivity Paradox: What do Computers do Productivity?', Canadian Journal of Economics, 32:2, pp. 309-334.

Watanabe, C., Zhu, B. and Miyazawa, T. (2001) 'Hierarchical Impacts of the Length of Technology Waves: An Analysis of Technolabor Homeostasis', Technological Forecasting and Social Change, 68:1, pp. 81-104.

Watanabe, C., Asgari, B. and Nagamatsu, A. (2003) 'Virtuous Cycle between R\&D Functionality Development and Assimilation Capacity for Competitive Strategy in Japan's Hightechnology Industry' Technovation, 23:11, pp. 879-900.

Watanabe, C. (2009) Co-evolutionary Dynamism between Innovation and Institutional Systems: The Rise and Fall of the Japanese System of Management of Technology, in: Tokyo Institute of Technology, The Science of Institutional Management of Technology: Elucidation of Japan's Indigenous Co-evolutionary Dynamism and Its Accrual to Global Assets. Tokyo Institute of Technology, Tokyo, pp. 21-34.

Watanabe, C., Nasuno, M. and Shin, J.H. (2011) 'Utmost Gratification of Consumption by means of Supra-functionality Leads a Way to Overcoming Global Economic Stagnation', Journal of Services Research, 11:2, pp. 31-58.

Watanabe, C., Zhao, W. and Nasuno, M. (2012) 'Resonance between Innovation and Consumers: Suggestions to Emerging Market Customers', Journal of Technology Management for Growing Economies, 3:1, pp. 7-31.

Watanabe, C. (2013) 'Innovation-consumption Co-emergence Leads a Resilience Business', Innovation and Supply Chain Management, 7:3, pp. 92-104.

Watanabe, C., Naveed, K. and Zhao, W. (2014) 'Institutional Sources of Resilience in Global ICT Leaders - Harness the Vigor of Emerging Power', Journal of Technology Management in Growing Economies, 5:1, pp. 7-34.

Watson, B. and McDonagh, D. (2004) 'Supra-functionality: Responding to Users Needs beyond

Journal of Technology Management for Growing Economies, Volume 5, Number 2, October 2014 
the Functional', Engineering Designer, 30 :5, pp. 8-11.

World Economic Forum (WEF) (2012) The Global Information Technology Report, WEF, Geneva.

World Economic Forum (WEF) (2013) The Global Information Technology Report, WEF, Geneva

World Telecommunication/ICT Indicators Database (2013) United Nations.

Chihiro Watanabe, National University of Singapore and University of Jyvaskyla, Finland. Email: watanabe.c.pqr@gmail.com.

Kashif Naveed, University of Jyväskylä, Finland. Email: kashif.naveed80@ yahoo.com

Weilin Zhao, Fujitsu Research Institute, Japan. Email: weilinzhao.chen@ gmail.com.
Structural Source

of the Trap

of ICT 